\title{
Efeitos Sobre o Tecido Ósseo e Cartilagem Articular Provocados Pela Imobilização e Remobilização em Ratos Wistar
}

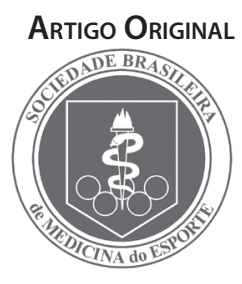

\section{Effects of Immobilization and Remobilization on Bone Tissue and Cartilage in Wistar Rats}

Danielle Portinho

Vinícius Guiselini Boin

Gladson Ricardo Flor Bertolin

Universidade Estadual do Oeste do Paraná (UNIOESTE) - Campus de

Cascavel - Paraná;

Endereço para correspondência: Gladson Ricardo Flor Bertolini Travessa Sebastião Pereira de Camargo, 69

Jardim Padovani. Cascavel - Paraná. CEP 85803-328

E-mail:

gladson_ricardo@yahoo.com.br

Submetido em 08/02/2007 Versão final recebida em 17/01/2008 Aceito em 25/01/2008

\section{RESUMO}

Longos períodos de imobilização conduzem à perda óssea e de propriedades do osso, e sua recuperação depende de vários fatores; além disso, a imobilização pode causar ulcerações no tecido cartilaginoso articular devido a alterações como perda de proteoglicanas, de massa e volume totais da cartilagem. O objetivo deste estudo foi verificar alterações histológicas, do tecido ósseo periarticular e da cartilagem articular, provocadas pela imobilização e remobilização de membros posteriores de ratos Wistar. Foram utilizados 12 ratos Wistar, divididos em dois grupos: $\mathrm{Gl}-(\mathrm{n}=6)$ : 15 dias com o membro posterior esquerdo imobilizado em plantiflexão, sendo o membro direito o controle; $G R-(n=6)$ : período de 15 dias de remobilização livre na gaiola, associado a três séries diárias de alongamento do músculo sóleo esquerdo por 30 segundos. Foram avaliados no tecido ósseo as medidas de espessura do osso cortical, diâmetro do canal medular e número de osteócitos; no tecido cartilaginoso, foram mensurados a espessura média da cartilagem e o número de condrócitos. Como resultado, observou-se que para Gl não houve alterações significativas na espessura do osso $(p=0,1156)$ nem no diâmetro do canal medular ( $p$ $=0,5698)$, mas diminuição significativa dos osteócitos em relação ao contralateral $(p=0,0005)$; em GR também houve decréscimo no número de osteócitos $(p=0,0001)$, mas as diferenças na espessura ( $p=$ $0,1343)$ e diâmetro do canal medular ( $p=0,6456)$ mantiveram-se não significantes. Para os dados de cartilagem articular não houve diferenças significativas para as amostras, tanto na espessura da cartilagem para GI $(p=0,6640)$ e $G R(p=0,1633)$, quanto no número de condrócitos em $G l(p=0,9429)$ e $G R$ ( $p=$ $0,1634)$. Conclui-se que duas semanas de imobilização e remobilização produziram apenas diminuição significativa no número de osteócitos nos ratos imobilizados; esse número continuou a diminuir mesmo nos animais remobilizados.

Palavras-chave: alongamento muscular, estresse articular, metabolismo ósseo.

\section{ABSTRACT}

Long immobilization periods lead to bone and properties loss, and its recovery depends on many factors. Besides that, immobilization can cause ulcerations in the articular cartilage tissue due to alterations, such as loss of proteoglycans and total cartilage mass and volume. The aim of this study was to verify histological alterations of the periarticular bone tissue and articular cartilage caused by immobilization as well as remobilization of hinder limbs of Wistar rats. Twelve Wistar rats were divided in two groups: Gl - $(n=6)$ : 15 days with the left hinder limb immobilized at plantiflexion, with the right limb being the control; $G R$ - ( $n=6)$ : used a 15 day-period of free remobilization in the cage, associated with 3 daily stretching bouts of the left soleus muscle for 30 seconds. The measures of the cortical bone thickness, diameter of the medular channel and number of condrocites were evaluated; in the cartilage tissue, the cartilage mean thickness and the number of condrocites were measured. The results showed that for $\mathrm{Gl}$ there were no significant alterations in the bone thickness $(p=0.1156)$, nor in the medular channel diameter $(p=0.5698)$, but there was significant decrease of the osteocytes compared with the counter-lateral side $(p=0.0005)$; in $G R$ decrease in the number of osteocytes ( $p=0.0001)$ was also observed, but the differences in thickness ( $p=0.1343)$ and medular channel diameter $(p=0.6456)$ remained non-significant. There were no significant differences for the articular cartilage data for the samples, neither in the cartilage thickness for $\mathrm{Gl}(\mathrm{p}=0.6640)$ and $\mathrm{GR}(\mathrm{p}=0.1633)$; concerning the number of condrocites in $\mathrm{Gl}(\mathrm{p}=0.9429)$ and $\mathrm{GR}$ ( $p=0.1634$ ). It is concluded hence that two weeks of immobilization and remobilization produced only significant decrease in the number of osteocytes in the immobilized rats and continued to decrease even in the remobilized animals.

Keywords: muscular stretch, articular stress, bone metabolism. 


\section{INTRODUÇÃO}

Juntamente com o tecido ósseo, o tecido cartilaginoso compõe o esqueleto, sendo uma forma especializada de tecido conjuntivo de consistência rígida. Desempenha a função de suporte de tecidos moles, reveste superfícies articulares onde absorve choques, facilita deslizamentos e é essencial para a formação e crescimento dos ossos longos. A cartilagem é composta de células chamadas condrócitos e de uma matriz extracelular altamente especializada; é um tecido avascular, sendo nutrida pelos capilares do conjuntivo envolvente (pericôndrio) ou através do líquido sinovial das cavidades articulares, como no caso da cartilagem articular ${ }^{(1,2)}$.

O tecido ósseo é um tecido dinâmico em constante remodelamento; tem por função: suportar partes moles, proteger órgãos, armazenar íons, apoiar músculos e produzir células sangüíneas. É um tipo especializado de tecido conjuntivo formado por células e material extracelular calcificado. A presença de matriz mineralizada torna o tecido ósseo difícil de ser cortado ao micrótomo; por isso, técnicas especiais são usadas no seu estudo. Uma das técnicas muito utilizadas baseia-se na descalcificação do tecido ósseo, após fixação com fixador histológico comum, o que possibilita o estudo das células desse tecido ${ }^{(1,3)}$.

De acordo com a lei de Wolff, cada mudança na função é seguida de mudanças na arquitetura interna e conformação externa do osso. O exercício ativo pode aumentar ou diminuir o peso, o comprimento e a idade?????? óssea, dependendo da idade, do gênero e outras características do indivíduo, assim como a intensidade, duração e tipo do exercício. Falta de exercícios, imobilidade, fraqueza ou lesão neuromuscular também afetam o tecido ósseo ${ }^{(4)}$. A perda óssea e de propriedades do osso são conhecidas após longos períodos de imobilização e sua recuperação varia com o tipo de imobilização, a idade, o osso, a espécie do animal, o tipo e a intensidade do exercício utilizado na fase de remobilização(5).

Longos períodos de imobilização podem causar ulcerações no tecido cartilaginoso articular, devido a alterações provocadas nesse tecido, tais como perda de proteoglicanas, de massa e volume totais da cartilagem ${ }^{(6)}$. Segundo Frateschi ${ }^{(7)}$, o tempo de remobilização deve ser maior que o período de imobilização para que as propriedades do tecido ósseo se recuperem por completo. Visto tais argumentos, urge a importância de estudos sobre o comportamento do tecido cartilaginoso, em especial da cartilagem articular, e do tecido ósseo periarticular, sob diferentes situações de remobilização.

O objetivo deste estudo foi verificar alterações histológicas, do tecido ósseo periarticular e cartilaginoso, provocadas pela imobilização de membros posteriores de ratos Wistar, e as modificações geradas nesses tecidos após remobilização livre acompanhada de alongamento do músculo sóleo, analisando variáveis como número das células e medidas da espessura dos tecidos.

\section{MÉTODOS}

No presente estudo foram utilizados 12 ratos Wistar, machos, com $12 \pm 2$ semanas de idade, os quais foram mantidos em gaiolas plásticas, com acesso a água e ração padronizada ad libitum, em fotoperíodo de 12 horas, obtidos do Biotério Central da Universidade Estadual do Oeste do Paraná. O estudo foi conduzido segundo as normas internacionais de ética em experimentação animal(8). A amostra foi dividida aleatoriamente em dois grupos:

Grupo $1(\mathrm{Gl})$ - $(\mathrm{n}=6)$ : neste grupo os animais permaneceram durante 15 dias com o membro posterior esquerdo imobilizado em plantiflexão, sendo após este período sacrificados.
Grupo $2(G R)$ - $(n=6)$ : neste grupo, além do período inicial de imobilização, foi utilizado um de 15 dias de remobilização livre na gaiola, associado a três séries diárias de alongamento do músculo sóleo esquerdo por 30 segundos, ou seja, estresse articular em dorsiflexão.

O protocolo de imobilização, para a manutenção de flexão plantar máxima, consistiu no uso de algodão e fita adesiva, além de um dispositivo (composto por malha de aço e tecido de algodão) de imobilização desenvolvido por Coutinho et al. ${ }^{(9)}$.

Para realizar o estresse de alongamento diário, os animais eram previamente sedados com éter etílico e posicionados em decúbito lateral, com as articulações do quadril e joelho a aproximadamente 90\%; a dorsiflexão era realizada até a sensação de estiramento de tecidos moles, por 30 segundos, e repetida por três vezes, sendo realizada sempre pelo mesmo pesquisador.

Após a fase de remobilização, os ratos foram anestesiados e sacrificados por decapitação em guilhotina e seus membros posteriores dissecados para coleta do material de estudo. A análise ocorreu no tecido ósseo periarticular e cartilagem articular da tíbia distal, nos 24 membros posteriores, sendo o direito o controle da pesquisa.

Os membros coletados foram fixados em formalina a 4\%. Após três a quatro dias de fixação, deu-se início à dissecação muscular do material, que visou à observação do tecido ósseo e cartilagem articular do tornozelo. Os membros coletados foram colocados em solução de ácido nítrico a 10\% por 20 dias, para a descalcificação do tecido ósseo.

O material então foi desidratado, diafanizado, impregnado e incluído em parafina para confecção dos blocos de inclusão. Após o preparo, o material foi levado ao micrótomo para realização de cortes histológicos $(0,8 \mu \mathrm{m})$. Foram confeccionados 24 blocos de parafina, através dos quais se realizaram cinco cortes de cada amostra. Os cortes foram colocados sob lâmina, corados com hematoxilina- eosina (HE) e em seguida cobertos com lamínula fixada à lâmina com permount.

Com as lâminas já confeccionadas, o material foi levado para análise microscópica em microscópio Olympus BX40, onde foram avaliadas características morfológicas e morfométricas dos tecidos.

As medidas de espessura do osso, diâmetro do canal medular e número de osteócitos foram realizadas em corte transversal da tíbia a aproximadamente 4-6mm de distância da articulação do tornozelo. Foram feitos cinco cortes de cada amostra; nesses cortes foram mensurados três pontos diferentes para a espessura do osso e o diâmetro do canal medular, e cinco campos visuais, aleatórios, por corte, para a contagem dos osteócitos. O corte longitudinal foi utilizado para a análise do tecido cartilaginoso, no qual foram mensurados a espessura média da cartilagem e o número de condrócitos. Com cinco cortes de cada amostra realizou-se a mensuração de três pontos na cartilagem articular: 1) anterior; 2) mediano e 3) posterior. Os condrócitos foram contados em cinco campos visuais, aleatórios, por corte. Depois de feito o levantamento desses dados, iniciou-se a análise estatística, que foi realizada pelo teste $t$ de Student pareado. $O$ valor de significância para todos os testes foi de $p<0,05$.

\section{RESULTADOS}

No Gl, duas semanas de imobilização do membro posterior esquerdo não provocaram alterações significativas na espessura do osso ( $p=$ 0,1156), nem no diâmetro do canal medular ( $p=0,5698$ ), com variações respectivas de 7,02\% e 3,64\% quando comparados os membros imobilizados e controle (figura 1). Entretanto, a imobilização provocou significativa diminuição dos osteócitos em relação ao contralateral, cuja variação foi de 24,34\% (figura 2; $p=0,0005$ ). 


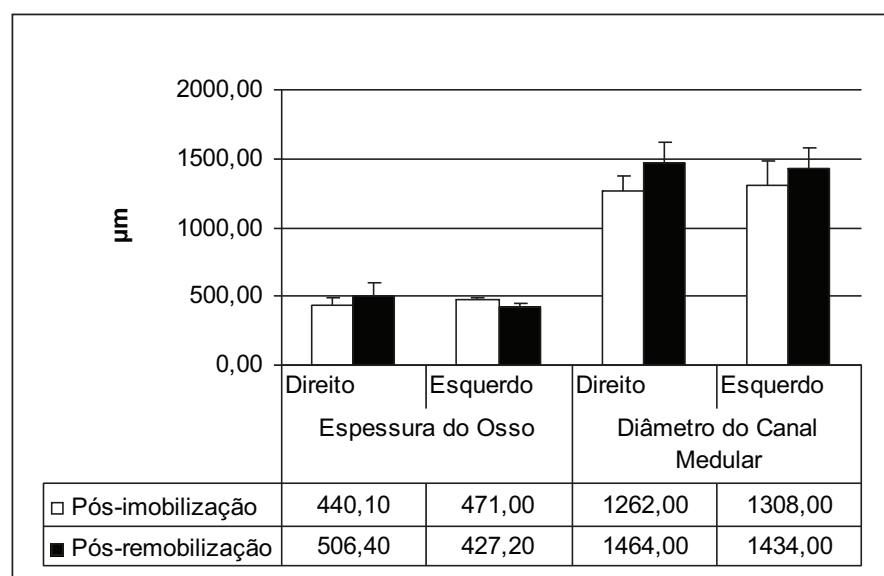

Figura 1. Diferenças nas medidas da espessura do osso e no diâmetro do canal medular do membro imobilizado em relação ao membro controle, pós-imobilização e pós-remobilização.

No segundo grupo de estudo (GR), o qual ficou imobilizado por duas semanas e sofreu posterior remobilização por igual período, decréscimo no número de osteócitos do tecido continuou ocorrendo, tanto no membro experimental como no livre. Provavelmente porque, ao final das duas semanas de imobilização, o tecido ainda estava sofrendo ação da deterioração ocorrida durante esse processo (figura 2; $p=0,0001)$; a variação sofrida pelo membro esquerdo em relação ao direito foi de 15,64\%. As medidas de espessura $(p=0,1343)$ e diâmetro do canal medular $(p=0,6456)$ não apresentaram diferença estatisticamente significativa, com variações de 15,64\% e 2,05\%, respectivamente (figura 1).

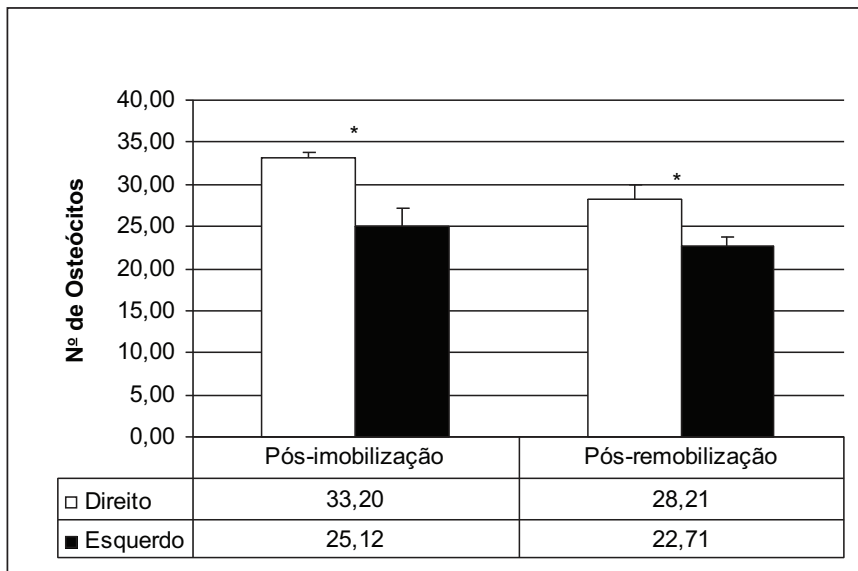

Figura 2. Diferença no número de osteócitos dos membros direito e esquerdo após um primeiro período de imobilização e um segundo período de imobilização e remobilização do membro. * Diferença significativa, $p<0,05$ (teste $t$ ).

Para os dados de cartilagem articular,não houve diferenças significativas para as amostras (figura 3 e 4).

A variação da espessura da cartilagem articular do membro posterior direito em relação ao membro posterior esquerdo dos animais imobilizados foi de 1,51\% ( $p=0,6640$ ), enquanto que, no grupo dos remobilizados, a variação foi de 6,43\% ( $p=0,1633$ ) (figura 3).

O número de condrócitos não apresentou diferença significativa, nem nos ratos imobilizados ( $p=0,9429$ ), nem nos ratos remobilizados ( $p=0,1634)$, cujas variações foram de $0,42 \%$ e 2,56\%, respectivamente.

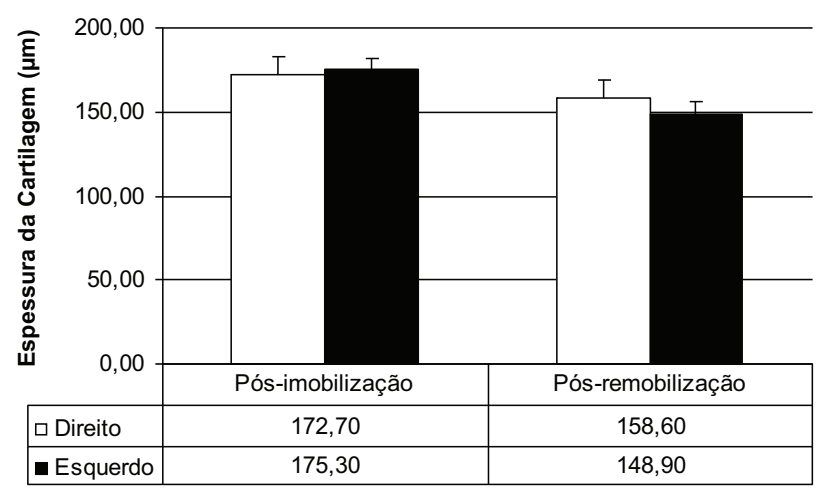

Figura 3. Espessura da cartilagem articular da porção distal da tíbia demonstrando os efeitos da imobilização e remobilização da articulação do tornozelo.

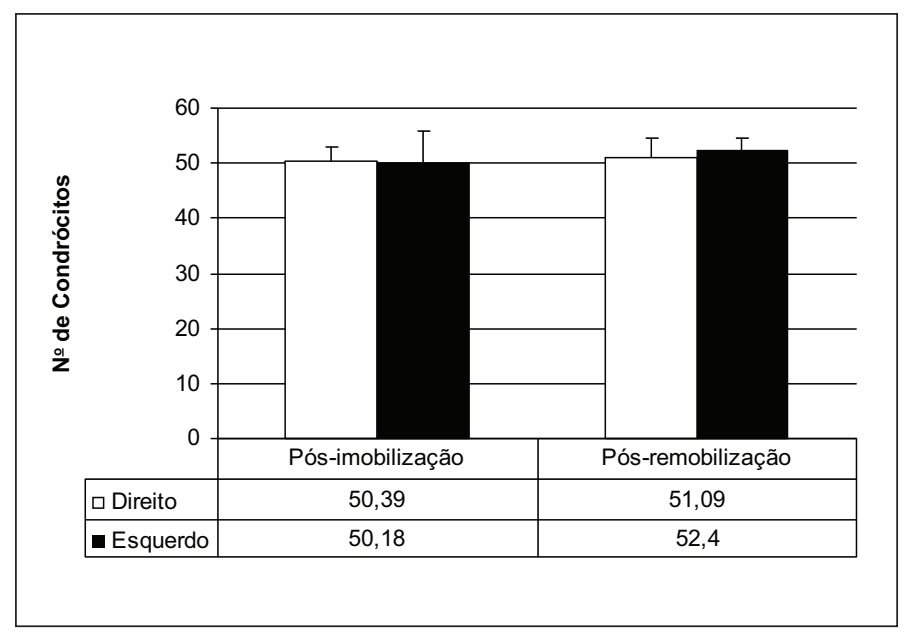

Figura 4. Número de condrócitos na cartilagem articular da porção distal da tíbia.

\section{DISCUSSÃO}

No presente estudo, duas semanas de imobilização não provocaram alterações significativas no diâmetro do canal medular, na espessura óssea, na espessura da cartilagem articular nem no número de condrócitos desse tecido. Entretanto, o número de osteócitos diminuiu significativamente nos ratos imobilizados e continuou a decrescer mesmo nos animais remobilizados. Esse resultado pode estar relacionado com a queda no metabolismo ósseo. provocando diminuição na quantidade de células para a manutenção desse tecido.

As características ósseas podem variar conforme o tempo de imobilização, de remobilização e a metodologia utilizada, bem como a espécie em estudo. Kaneps et al. ${ }^{(5)}$ estudaram cães adultos imobilizados por 16 semanas. Estes só tiveram completa recuperação após 32 semanas de remobilização. No estudo de Trebacz ${ }^{(10)}$, em ratos adultos jovens, após duas semanas de imobilização houve mudança significativa na massa e na densidade óssea, embora a mineralização fosse a mesma em ambos os membros. Após quatro semanas de remobilização a rigidez era significativamente mais baixa nos membros remobilizados que nos membros controle. Duas semanas de imobilização do tornozelo não influenciaram nem a espessura do fêmur, nem a área do canal medular; a mineralização do tecido ósseo também não foi afetada.

Diferente de outras espécies, os Ursus americanus podem manter sua formação óssea mesmo em situações de desuso, como no período 
de hibernação. Possivelmente, isso se deve ao fato de esses animais conseguirem manter a formação osteoblástica do tecido durante a imobilização, além de recuperar rapidamente, na remobilização, o osso perdido. Outras espécies, porém, requerem períodos três a quatro vezes maiores ${ }^{(11)}$

Os processos de imobilização provocam alterações ósseas que se seguem mesmo após um primeiro momento de remobilização. Como conseqüência disso, o osso cresce mais fraco, apesar da restauração da atividade normal(12). A remobilização pode adicionar tecido ósseo apenas em superfície existente, não sendo suficientemente anabólica para reconectar trabéculas ósseas perdidas durante a imobilização(13)

Os resultados obtidos no presente estudo corroboram os descritos por Trebacz e Zdunek ${ }^{(12)}$, de que o processo de desuso promove a degradação do osso no esqueleto adulto e não retorna imediatamente após a restauração da atividade. É sabido que a privação de estresse altera as características morfológicas, bioquímicas e biomecânicas da cartilagem articular ${ }^{(14)}$. Entretanto, o fato de não terem ocorrido alterações na cartilagem articular está de acordo com o trabalho de LeRoux et al.(15), os quais demonstraram que as propriedades mecânicas da cartilagem, nos membros imobilizados sofrem alterações após um período de quatro semanas de imobilização comum.

Renner. ${ }^{(16)}$, de forma semelhante à do presente estudo, avaliaram alterações na cartilagem articular de tornozelos de ratos, após protocolo de alongamento muscular passivo cíclico em animais previamente imobilizados por quatro semanas. $O$ protocolo de alongamento uti- lizado foi repetição de 10 vezes de dorsiflexão manual por 60s com 30s de intervalo entre cada período, sete dias por semana, por três semanas. Como resultados, não observaram nenhum efeito significativo no grupo apenas alongado; contudo, no grupo imobilizado e alongado houve redução significativa de conteúdo de proteoglicanas, e a análise morfométrica mostrou aumento na celularidade sem alteração na espessura, comparada com o controle. Concluíram que o protocolo de alongamento usado foi prejudicial para a cartilagem articular previamente imobilizada.

Vistas as diferenças nos períodos de imobilização e no protocolo de alongamento, não foram observados no presente estudo resultados semelhantes aos descritos acima, pois não foram verificadas alterações significativas no número de condrócitos no membro imobilizado ao comparar com o contralateral e, de forma semelhante, também não se constataram alterações na espessura da cartilagem articular.

Para o presente estudo, objetivou-se analisar se a adição do estresse de estiramento muscular e articular produziria retorno dos parâmetros variantes durante a imobilização, em tempo semelhante de remobilização e imobilização, fato não observado para o número de osteócitos que, durante a imobilização, apresentou variação significativa ao comparar com o membro controle, bem como no período de remobilização.

Todos os autores declararam não haver qualquer potencial conflito de interesses referente a este artigo.

\section{REFERÊNCIAS BIBLIOGRÁFICAS}

1. Junqueira LC, Carneiro J. Histologia básica. 9a. ed. Rio de Janeiro: Guanabara Koogan, 1999.

2. Stevens A, Lowe J. Histologia humana. 2a. ed. São Paulo: Manole, 2001.

3. Spence AP. Anatomia humana básica. 2a. ed. São Paulo: Manole, 1991.

4. Cornwall MW. Biomechanics of noncontractile tissue - a review. Phys Ther 1984;63:1869-73

5. Kaneps SJ, Stover SM, Lane NE. Changes in canine cortical and cancellous bone mechanical properties following immobilization and remobilization with exercise. Bone 1997;21:419-23.

6. Lantz CA. Immobilization degeneration and the fixation hypothesis of chiropractic subluxation. A review of the literature related to the degeneration of connective tissue following joint immobilization: implications concerning the fixation hypothesis of chiropractic subluxations. Chiropractic Res J 1998;1:21-46

7. Frateschi MEBJM. Efeitos da imobilização e remobilização em algumas propriedades mecânicas do osso [Dissertação de Mestrado em Bioengenharia]. Instituto de Química de São Carlos: Universidade de São Paulo, 2002

8. Andersen ML, D'Almeida V, Ko GM, Kawakami R, Martins PJF, Magalhães LE, et al. Princípios éticos e práticos do uso de animais de experimentação. São Paulo: UNIFESP - Universidade Federal de São Paulo, 2004.
9. Coutinho EL, Gomes ARS, França CN, Salvini TF. A new model for the immobilization of the rat hind limb. Braz J Med Biol Res 2002;35:1329-32.

10. Trebacz H. Disuse-induced deterioration of bone strength is not stopped after free remobilization in young adult rats. J Biomech 2001;34:1631-6.

11. Harvey K, Donahuea SW. Bending properties, porosity, and ash fraction of black bear (ursus americanus) cortical bone are not compromised with aging despite annual periods of disuse. J Biomech 2004;37:1513-20.

12. Trebacz $\mathrm{H}$, Zdunek A. Three-point bending and acoustic emission study of adult rat femora after immobilization and free remobilization. J Biomech 2006;39:237-45.

13. Ijiri K, Jee WSS, Ma YF, Yuan Z. Remobilization partially restored the bone mass in a nongrowing cancellous bone site following long term immobilization. J Biomech 1995;17:213-7.

14. Vanwanseele B, Lucchinetti E, Stüssi E. The effects of immobilization on the characteristics of articular cartilage: current concepts and future directions. OsteoArthritis Cartilage 2002;10:408-19.

15. LeRoux MA, Cheung HS, Bau JL, Wang JY, Howell DS, Setton LA. Altered mechanics and histomorphometry of canine tibial cartilage following joint immobilization. OsteoArthritis Cartilage 2001;9:633-40.

16. Renner AF, Carvalho E, Soares E, Mattiello-Rosa S. The effect of a passive muscle stretching protocol on the articular cartilage. OsteoArthritis Cartilage 2006;14:196-202. 